\title{
Electrofishing eel, salmon and trout: impact of waveform and frequency on capture-per-unit-effort and spinal damage
}

\author{
Gaétan Pottier ${ }^{1,2,3, *}$, Marie Nevoux ${ }^{2,4}$ and Frédéric Marchand ${ }^{1,2}$ \\ ${ }^{1}$ Ecologie et Ecotoxicologie Aquatique, INRAE, Rennes, France \\ ${ }^{2}$ Management of Diadromous Fish in their Environment, OFB, INRAE, Agrocampus Ouest, Univ Pau Pays Adour, Rennes, France \\ ${ }^{3}$ Hydréco Guyane, Laboratoire Environnement de Petit Saut, Kourou, France \\ ${ }^{4}$ Ecology and Ecosystem Health, INRAE, Agrocampus Ouest, Rennes, France
}

Received: 29 July 2020 / Accepted: 31 October 2020

\begin{abstract}
Performing fish survey protocols with different electrofishing equipment and settings can lead to difficulties in comparing the data obtained. In this study, we captured two fish taxa (i.e. the European eel and salmonids: Atlantic salmon and brown trout) in the field using four models of electrofishers that provided different waveforms: direct current (DC), pulsed direct current (PDC) and pulsed exponential current (PEC). This study aimed to assess effects of using different waveforms and frequencies, while considering environmental variables, on i) attraction, represented by occurrence and catch-per-unit-effort (CPUE) of fishes, and ii) spinal damage, based on ultrasound of the spinal column. For all species, DC and PDC yielded equivalent occurrences and CPUEs, regardless of the frequency. In contrast, PEC induced a significant decrease in occurrences and CPUEs of both eels and salmonids. The percentage of injured fishes increased as the frequency or length of the salmonids increased while waveform had no effect. Ultrasound was determined to be a good non-invasive method to detect injuries in fishes.
\end{abstract}

Keywords: Electrofishing / waveform / current frequency / catch-per-unit-effort / spinal damage

Résumé - Pêche électrique d'anguilles, de saumons et de truites : impact de la forme du courant et de la fréquence sur la capture-par-unité-d'effort et les dommages vertébraux. La réalisation de protocoles de suivi de poissons avec différents équipements de pêche électrique et différents réglages peut entrainer des difficultés pour comparer les données obtenues. Dans cette étude, nous avons capturé deux taxons de poissons (c.-à-d. l'anguille européenne et les salmonidés : le saumon Atlantique et la truite fario) sur le terrain à l'aide de quatre modèles d'engins de pêche électrique qui fournissaient différentes formes de courant : le courant continu (DC), le courant continu pulsé (PDC) et le courant pulsé exponentiel (PEC). Cette étude visait à évaluer les effets de l'utilisation de différentes formes de courant et fréquences, tout en tenant compte des variables environnementales, sur i) l'attraction, représentée par l'occurrence et la capturepar-unité-d'effort (CPUE) des poissons, et ii) les dommages vertébraux, sur la base de l'échographie de la colonne vertébrale. Pour toutes les espèces, le DC et le PDC ont donné des occurrences et des CPUEs équivalentes, quelle que soit la fréquence. En revanche, le PEC a induit une diminution significative des occurrences et des CPUEs des anguilles et des salmonidés. Le pourcentage de poissons blessés augmentait à mesure que la fréquence ou la longueur des salmonidés augmentait, tandis que la forme du courant n'avait aucun effet. L'échographie s'est avérée être une bonne méthode non invasive pour détecter les blessures chez les poissons.

Mots clés : Pêche électrique / forme de courant / fréquence du courant / capture-par-unité-d'effort / dommage vertébral

\footnotetext{
*Corresponding author: gaetan.pottier@hydrecolab.com
} 


\section{Introduction}

Electrofishing is the method most widely used to assess fish assemblages in streams throughout the world (Bozzetti and Schulz, 2004; Tomanova et al., 2013; Jha et al., 2018; Wellemeyer et al., 2018). In wadeable streams, this method of capture is particularly valuable due to its speed of operation, the small number of operators needed and its ability to obtain higher species richness and abundance than those of set nets (Growns et al., 1996; Penczak et al., 1998) or seines (Penczak et al., 1998). Fishes caught by electrofishing may have a low risk of injury (Snyder, 2003).

Electrofishers can provide different waveforms such as direct current (DC), pulsed direct current (PDC) or pulsed exponential current (PEC, a condenser discharge), at different voltages. The existence of many models of electrofishers can raise the issue of the accuracy of monitoring and comparisons over time when equipment is changed. This difference in electrofishers can generate difficulties in comparing the data obtained with different devices. Moreover, not all environmental factors can be controlled when electrofishing. For instance, capture efficiency can decrease as depth increases (Bohlin et al., 1989), and some species' habitat preferences can influence the number of fishes caught. The range of possible settings of the electrofisher can influence on the radius of attraction (RADAC) and fish injury. Consequently, an electrofisher must be configured accurately to ensure robust surveys, but few guidelines are available for researchers and managers.

To our knowledge, only two studies tested the influence of the waveform on capture efficiency. Beaumont et al. (2000) demonstrated under experimental conditions that PDC captured rainbow trout more efficiently than PEC but that the shape of PDC at a given power had no influence. Moreover, Chiaramonte et al. (2020) found a difference in the probability of capturing trout between two PDC frequencies $(30 \mathrm{~Hz}$ and $60 \mathrm{~Hz}$ ). Some points still need to be explored, such as the effect of DC on the ability to catch fishes and the relation between higher frequency and injury to fishes.

Although electrofishing is an efficient method for catching fishes, it can injure them (Gatz et al., 1986; Sharber and Carothers, 1988; Mesa and Schreck, 1989; Hollender and Carline, 1994; Snyder, 2003). These injuries are caused when fishes are located in the tetanus zone, which is the zone closest to the anode, where the voltage gradients are highest (Snyder, 2003). Increasing the voltage gradient of an electric field induces an increase in mortality (Lamarque, 1990). Waveform also influence fishes: for instance, PDC and PEC are less harmful than real alternating current and its derived shapes (Sharber and Carothers, 1988). Increasing the frequency of PDC incrementally increases the percentage of injured fishes (McMichael, 1993; Sharber et al., 1994; Dalbey et al., 1996; Dolan et al., 2002).

Electrofishers should therefore be configured based on a compromise between capture efficiency and the fish welfare. In this way, the ideal electric setting in water aims to catch fishes efficiently while decreasing impacts on their survival. However, no comprehensive guidelines are currently available on the specific effects of different waveforms and frequencies on the catchability of and impact on fishes. Although previous

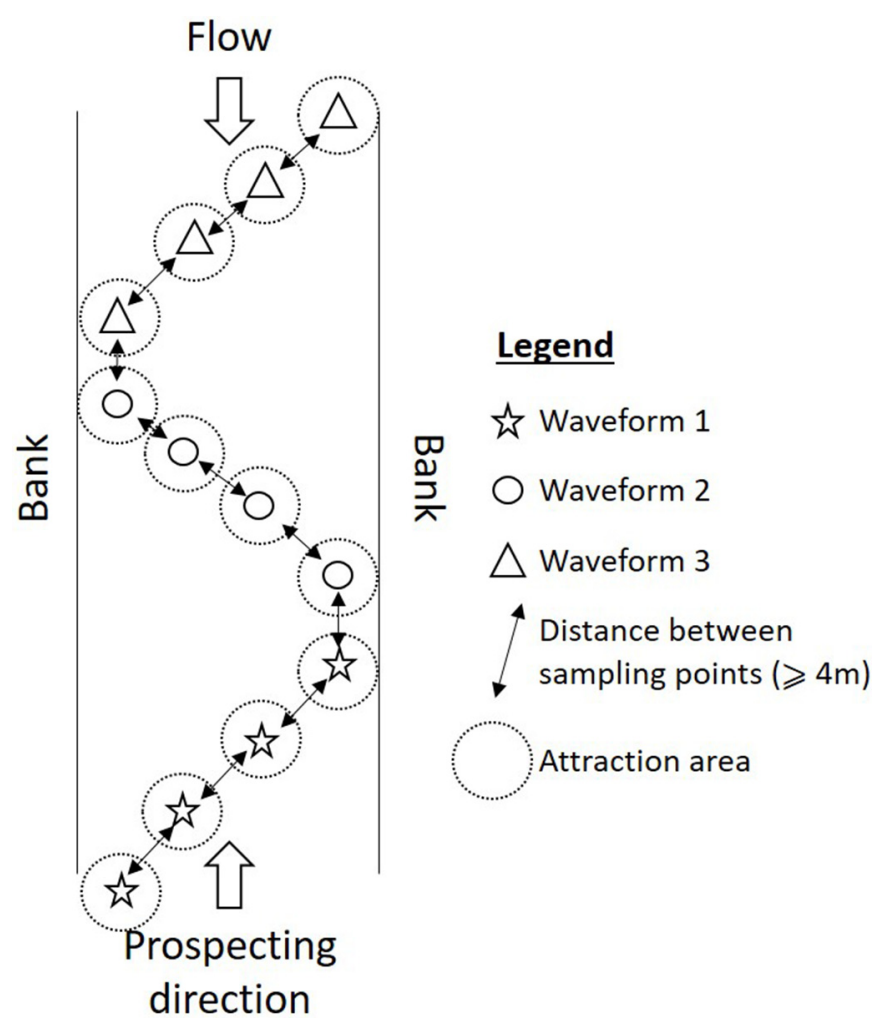

Fig. 1. General sampling design for catching eels and salmonids. Each symbol represents one sampling point. Each waveform was produced by a different electrofisher.

studies were conducted under experimental conditions, few results are available from studies conducted in the wild, where environmental factors can influence fish behaviour (e.g. presence of shelter) and thus capture efficiency. Catchability can also vary among fish species (Vehanen et al., 2013). To fill this gap, the objective of our study was to investigate effects of waveforms (DC, PDC and PEC) and frequencies (range: $0-$ $400 \mathrm{~Hz}$ ) on i) attraction of and ii) spinal damage to fishes iii) by species and iv) modulated by the environment. We considered two taxa that are bioindicators of stream quality: the European eel Anguilla anguilla (Linnaeus, 1758) and salmonids (Atlantic salmon Salmo salar (Linnaeus, 1758) and brown trout Salmo trutta fario (Linnaeus, 1758)). To meet these goals, two survey protocols were performed: the eel abundance index (EAI) and salmonid abundance index (SAI).

\section{Materials and methods}

\subsection{Experimental protocol}

In both protocols, the operator waded upstream to sampling points. The sampling protocol consisted of sampling points along a predefined zigzag trajectory from one bank to the other (Fig. 1). This design ensured an even sampling effort, regardless of stream width. The sampling points were separated by at least $4 \mathrm{~m}$ to ensure that the attraction fields did not overlap each other. The target species hid near the electric field and could be caught easily. Forty-eight sampling 
points were used per waveform. The waveforms were emitted in the stream, each at four consecutive sampling points, in a random order by a given electrofishers: waveform 1 was emitted at four points by operator $\mathrm{A}$, then waveform 2 was emitted at four points by operator B, etc. (Fig.1). Because each operator had his/her own fishing behaviour, which could have biased the results, the four operators exchanged electrofishers every 12 sampling points per waveform. In the first rotation, waveform 1 was emitted at four points by operator B, then waveform 2 was emitted at four points by operator $C$, etc. In each EAI and SAI, the two net carriers remained unchanged for all sampling points to maintain a constant fishing effort.

At each sampling point, all fishes seen were caught. For the EAI, the survey was performed out by emitting electricity into the water at each sampling point for 30 seconds (measured with a stopwatch). For the SAI, the sampling points consisted of transects $2 \mathrm{~m}$ long with electricity emitted into the water for 8 seconds. This design yielded in comparable sampling points (i.e. a similar effort for each protocol). Each fish was identified to the species level and measured (fork length for salmonids and total length for eels).

\subsection{Study sites}

Each protocol was performed on a different day in one wadeable section of a river (depth $<60 \mathrm{~cm}$ ). Habitat was described (visual estimation and depth measurement) at each sampling point after passage of the anode to include it as a potential factor that influenced the results. Environmental variables of the habitats varied among combinations of protocol and waveform (Tab. 1). The EAI protocol was performed in the Odet River in north-western France $\left(47^{\circ} 59^{\prime} 44.7^{\prime \prime} \mathrm{N} 4^{\circ} 05^{\prime} 20.1^{\prime \prime} \mathrm{W}\right)$ in June 2016. The ambient conductivity of the water was $145 \mu \mathrm{S} \mathrm{cm}^{-1}$. Mean stream width was $15.3 \mathrm{~m}$. Two SAIs were performed in 2015 (SAI-2015) and 2017 (SAI-2017), respectively. Both SAIs were performed in the Oir River in north-western France $\left(48^{\circ} 38^{\prime} 17.0^{\prime \prime} \mathrm{N} 1^{\circ} 11^{\prime} 06.6^{\prime \prime} \mathrm{W}\right)$ in September. The ambient conductivity of the water was 184 and $207 \mu \mathrm{S} \mathrm{cm}^{-1}$ for SAI-2015 and SAI-2017, respectively. Mean stream width was $3.4 \mathrm{~m}$.

\subsection{Selection and adjustment of waveforms}

Four backpack electrofishers were used to produce the waveforms (Fig. 2) and frequencies. The DC was produced by a Hans Grassl ELT60II, PEC (induced by discharging a capacitor with a capacity of $4 \mu \mathrm{F}$, with the pulse width depending on the conductivity) was produced by an IMEO Volta and PDC was produced by a Smith-Root LR-24 and a Dream Electronique Martin-Pêcheur (Tab. 2). The pulse width (i.e. how long the signal exceeds $0 \mathrm{~V}$ ) was measured with an oscilloscope (Industrial Scopemeter Fluke ${ }^{\circledR}$ ).

For the EAI, pulsed currents were set at the optimal frequency $(20 \mathrm{~Hz})$ to catch eels, based on the protocol developed by Halsband (1968). However, $400 \mathrm{~Hz}$ is also an optimal frequency according to Gosset et al. (1971). As the Martin-Pêcheur can be adjusted only through battery power, it was set to $50 \%$ of the battery power and a frequency of $400 \mathrm{~Hz}$, which are usual typical settings for the EAI protocol (Germis, 2016).

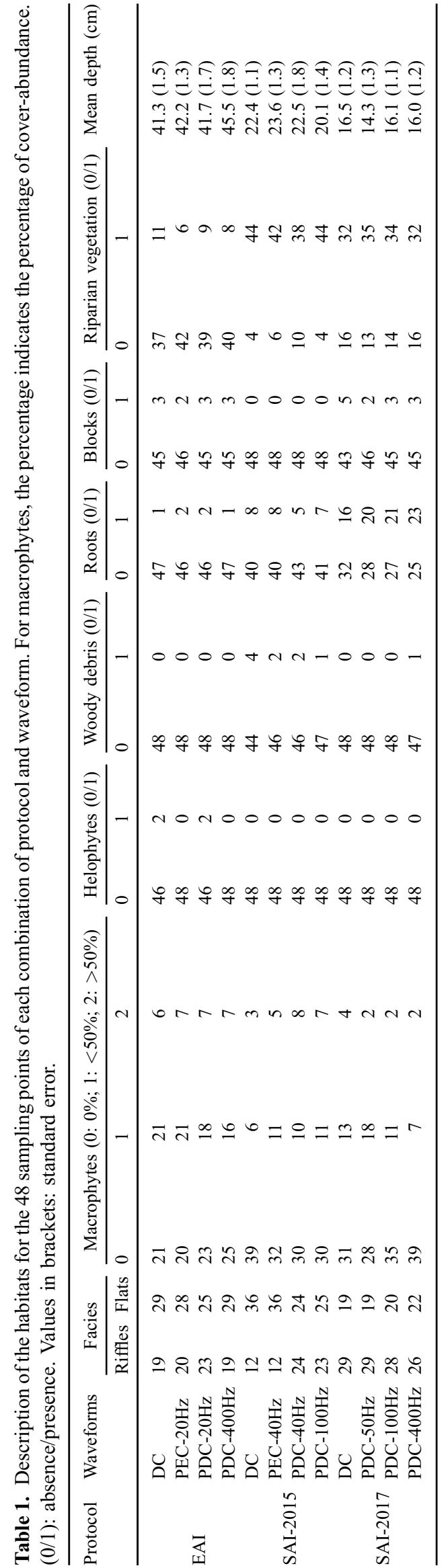



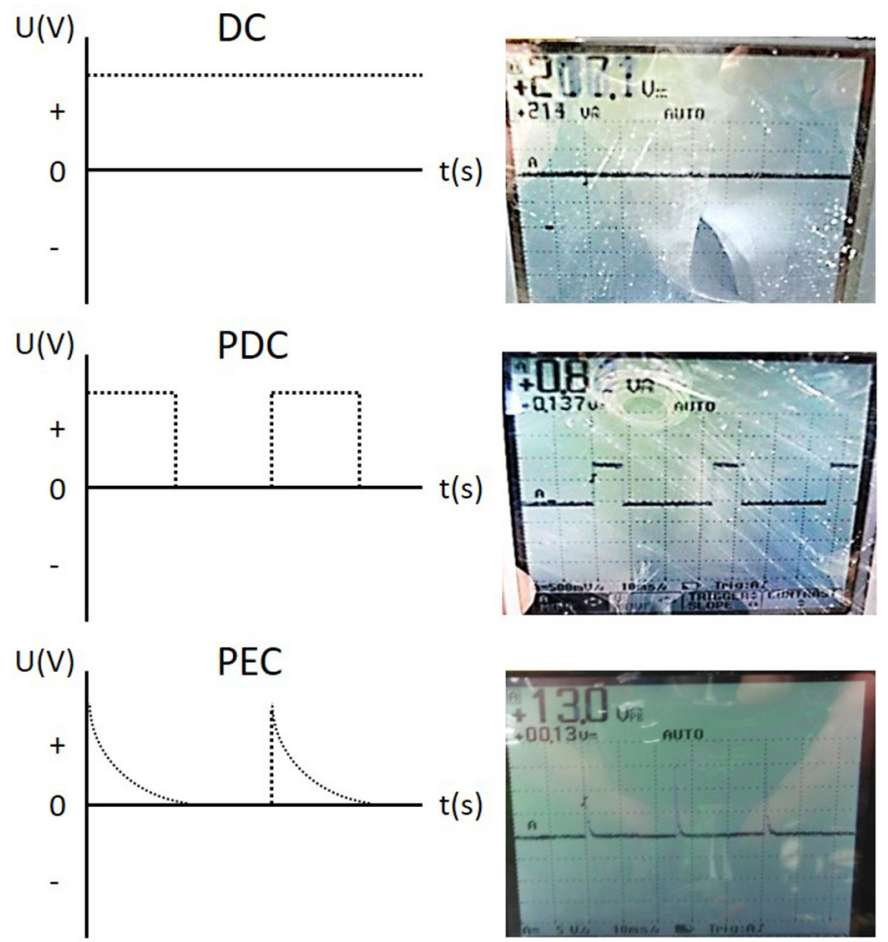

Fig. 2. Waveforms (diagram and field picture) used in this study (dotted lines). DC: direct current. PDC: pulsed direct current. PEC: pulsed exponential current. U: voltage. t: time.

During the SAIs, multiple frequencies were used to assess effects of a complete range of frequencies on the attraction of and the impact on fish. For SAI-2015, the pulsed currents were set at a recommended frequency $(40 \mathrm{~Hz})$ to catch salmonids (10-60 Hz; Beaumont, 2011). Again the Martin-Pêcheur was adjusted to $50 \%$ of the battery power, which is the usual setting for the abundance salmons index protocol (Prévost and Baglinière, 1995). Its frequency was set at $100 \mathrm{~Hz}$ (which attracted trout the most, according to Lamarque, 1968). For SAI-2017, the frequency of LR-24 was set at $50 \mathrm{~Hz}$, which is an intermediate frequency for catching salmonids. The frequencies of two Martin-Pêcheurs were set at $100 \mathrm{~Hz}$ and $400 \mathrm{~Hz}$ to assess whether results differed at high frequencies.

When electrofishing, the easiest way to determine the attraction of the electric field is to assess the theoretical RADAC around the anode with the following voltage gradient: $0.1 \mathrm{~V} \mathrm{~cm}^{-1}$. This value is the theoretical detection threshold of attraction for DC and PDC for conductivity in the range of 100-10,000 $\mu \mathrm{S} \mathrm{cm}^{-1}$ (Cuinat, 1968; Kolz and Reynolds, 1989; Lamarque, 1968; Snyder, 2003). For all of the protocols, the voltage was adjusted to create an equal RADAC (i.e. the same

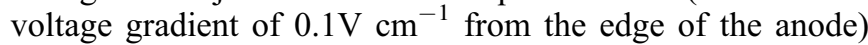
(Tab. 2). The RADAC was adjusted as a function of the usual settings of the Martin-Pêcheur. The voltage gradient was measured using a "penny" probe (term defined by Beaumont (2011)) connected to an oscilloscope (Industrial Scopemeter Fluke $\left.^{\mathbb{R}}\right)$. Because of the uncontrollable environment and the difficulty in maintaining a constant voltage gradient in a natural environment, and because propagation of the voltage gradient depends on the duty cycle (Pottier et al., 2020), RADAC was measured four times for each waveform (Tab. 2).
Voltage was adjusted to match the RADAC of the MartinPêcheur (Tab. 2) throughout the survey. The power density associated with the RADAC was then calculated according to Kolz (1989). All electrofishers had the same anode diameter $(35 \mathrm{~cm})$ to remove bias caused by operation.

\subsection{Catch-per-unit-effort}

The catch-per-unit-effort (CPUE) indicated attraction to the anode, fish abundance and capture efficiency and whether they were influenced by environmental variables, the waveforms or frequency. For the EAI and SAI protocols, CPUE was expressed as the number of individuals per 30 or 8 seconds, respectively, of emitting of electricity into the water.

\subsection{Damage quantification}

To analyse internal damage, sub-samples of fishes from each waveform tested were haphazardly selected (to attempt to avoid bias) for examination. Fifty-five (18.5\%) of the 297 eels caught and $585(89.6 \%)$ of the 653 salmonids caught were examined. Spinal injuries were visualized using an ultrasound system (Sonosite M-Turbo) with a 10-5 Mhz transducer. This equipment was portable, which allowed fishes to be scanned within minutes of capture. Spinal injuries consisted of compressed, misaligned or fractured vertebrae (Fig. 3). Injured fishes were noted. Only spinal injuries were recorded because the ultrasound system is non-invasive, which allowed the operators to release fishes alive.

\subsection{Statistical analysis}

Generalised linear models (GLMs) were built to test effects of the waveform, frequency, environmental variables and length of fishes on the CPUE and the occurrence of injured fishes. For data analysis, DC was considered as PDC with a frequency of $0 \mathrm{~Hz}$.

For the CPUE data, the delta method (Maunder and Punt, 2004) was applied to address the large number of zero catches. First, we modelled the probability of obtaining a non-zero catch. The occurrence of fishes (presence/absence) was modelled using a GLM with a binomial distribution of error (link: logit). The predictors were the environmental variables, waveform, frequency and operator. For the SAIs, because the data consisted of two species and two years of sampling, the proportion of salmon and the year (nested effect with power density) were added as predictors.

Second, we modelled the catch rate within non-null CPUE sampling points. The variation in CPUE was analysed as a function of a set of predictors using a GLM that included a Poisson distribution error (link: $\log$ ). The predictors were the environmental variables, waveform, frequency, mean fish length per sampling point and operator. For the SAIs only, the proportion of salmon and the year were also added as predictors.

For the SAIs, the occurrence of injured fishes was analysed using a GLM with a binomial distribution of error (link: logit). Because of the small number of injured fishes, degrees of spinal damage were not differentiated. The predictors were the environmental variables, frequency, power density, fish length, 
G. Pottier et al.: Knowl. Manag. Aquat. Ecosyst. 2020, 421, 42

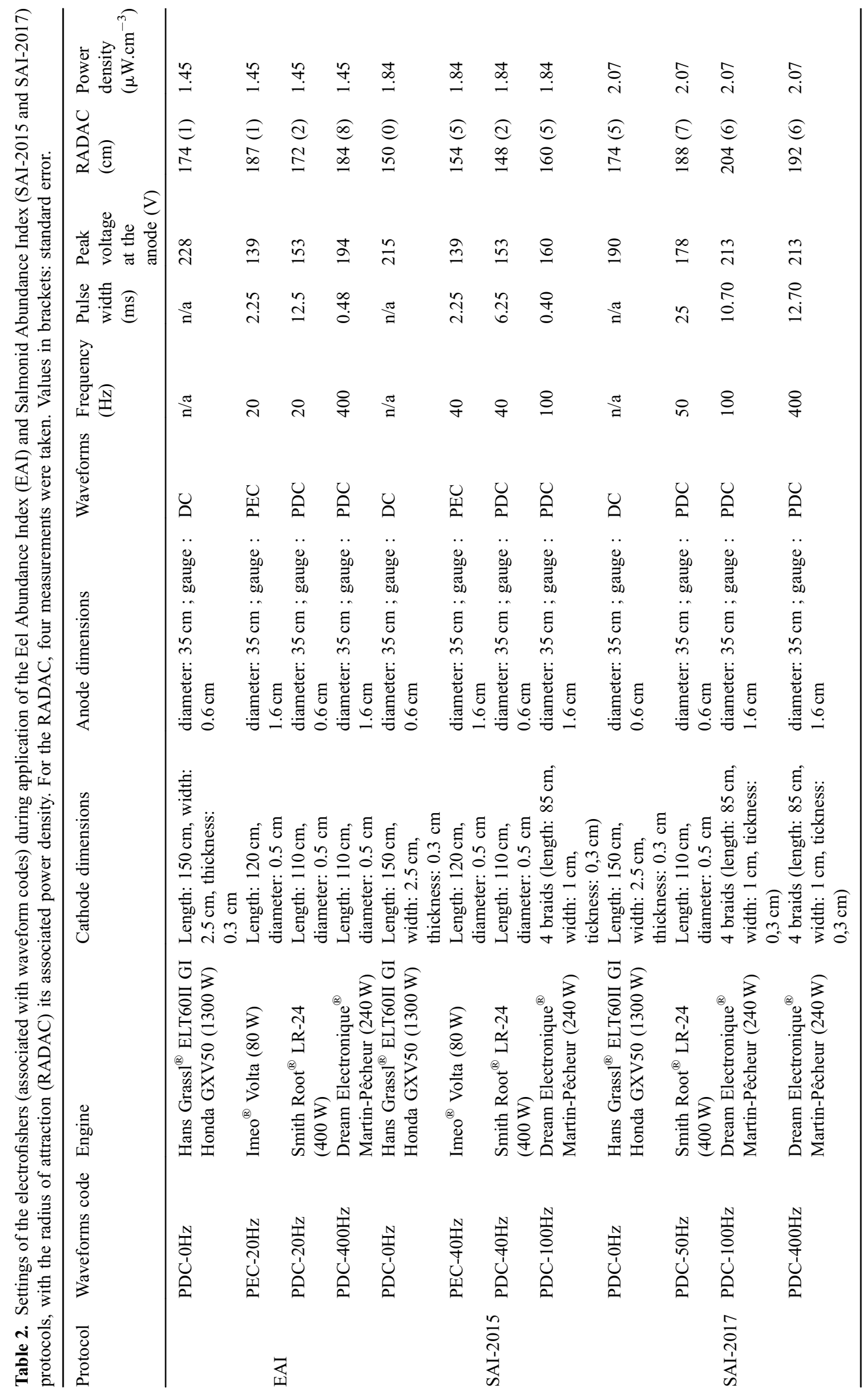




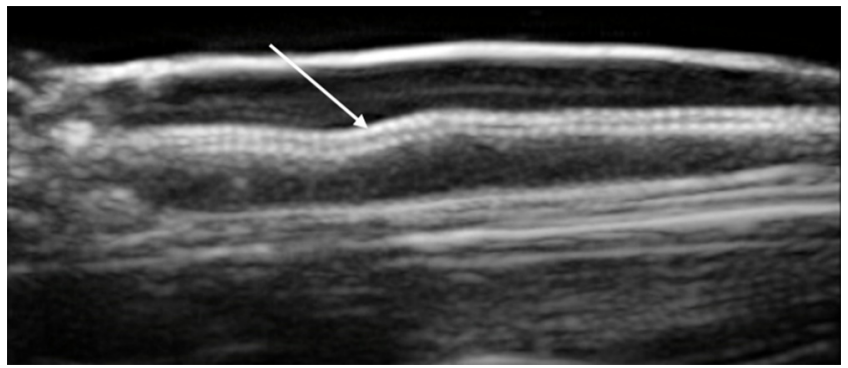

Fig. 3. Ultrasound image of a spinal column of a brown trout. The arrow indicates misalignment of the spinal column. The fish is placed on its left flank, with the head on its left side of the image.

Table 3. Modelling the (A) occurrence and (B) non-null CPUE of European eels using the Eel Abundance Index protocol, as a function of environmental variables and waveforms. N: 192. With Cohen's effect: 0.2 ; statistical power: 1 .

\begin{tabular}{lclcc}
\hline (A) & Estimate & $\begin{array}{l}\text { Standard } \\
\text { Error }\end{array}$ & $\mathrm{Z}$ value & $\mathrm{P}$ value \\
\hline Intercept & 4.29 & 0.909 & 4.71 & $<0.001$ \\
Depth & -0.068 & 0.019 & -3.60 & $<0.001$ \\
PEC waveform & -3.92 & 0.59 & -6.70 & $<0.001$ \\
\hline (B) & Estimate & Standard & $\mathrm{Z}$ value & $\mathrm{P}$ value \\
& & Error & & \\
\hline Intercept & 1.84 & 0.21 & 8.67 & $<0.001$ \\
Riparian vegetation & -0.34 & 0.16 & -2.08 & 0.04 \\
Depth & -0.020 & 0.0053 & -3.88 & $<0.001$ \\
PEC waveform & -1.07 & 0.50 & -2.13 & 0.03 \\
\hline
\end{tabular}

species, operator and year. We did not perform this analysis for the EAI survey because of the low percentage of eels examined with ultrasound and the low occurrence of injuries detected within this subsample. The EAI data are presented only for information.

For each model, we used stepwise backward elimination to identify the significant predictors: analysis of variance of these models was performed, starting with the most complex model, and predictors were removed until only significant ( $\mathrm{p}$ value $<0.05$ ) ones were left. Residuals were verified using Q-Q plots and binned residual plots (Gelman and Yu-Sung, 2018). Data were analysed using R software v.3.3.2 (R Development Core Team, 2011).

\section{Results}

\subsection{Catch-per-unit-effort}

During the EAI, 297 eels were caught. Eel occurrence decreased significantly as water depth increased (Tab. 3A). Waveform influence CPUE significantly (Tab. 3). PEC detected significantly fewer fishes (by a factor of 8-10) than other waveforms (Fig. 4A). Moreover, non-null CPUE decreased as depth increased, when the vegetation was present and when using PEC (Tab. 3B). The CPUE was higher in shallow habitats, but PEC was less efficient at capturing fishes regardless of the habitat (Fig. 4B).

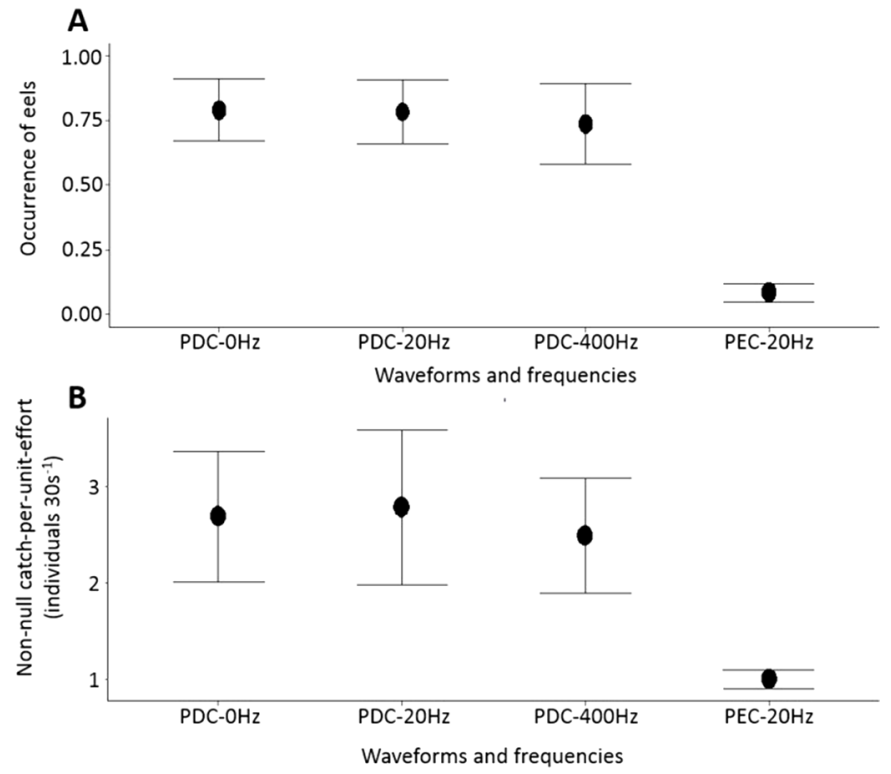

Fig. 4. Estimates of the (A) occurrence and (B) non-null catch-perunit-effort of eels by waveform and frequency. Results are means \pm 1 SD. N: 192. With Cohen's effect: 0.2; statistical power: 1 .

Table 4. Modelling the (A) occurrence of salmonids and (B) the nonnull CPUE of salmonids, using the Salmonids Abundance Index protocol, as a function of environmental variables and waveforms. N: 384. With Cohen's effect: 0.2; statistical power: 1.

\begin{tabular}{lclcc}
\hline A) & Estimate & $\begin{array}{l}\text { Standard } \\
\text { Error }\end{array}$ & $\mathrm{Z}$ value & $\mathrm{P}$ value \\
\hline Intercept & 0.011 & 0.25 & 0.05 & 0.96 \\
Roots & 0.96 & 0.29 & 3.36 & $<0.001$ \\
Depth & 0.035 & 0.013 & 2.72 & $<0.01$ \\
PEC waveform & -1.73 & 0.35 & -4.91 & $<0.001$ \\
\hline (B) & Estimate & Standard & $\mathrm{Z}$ value & $\mathrm{P}$ value \\
& & Error & & \\
\hline Intercept & 0.42 & 0.13 & 3.38 & $<0.001$ \\
Roots & 0.20 & 0.085 & 2.35 & 0.02 \\
Depth & 0.015 & 0.0042 & 3.47 & $<0.001$ \\
PEC waveform & -0.51 & 0.23 & -2.20 & 0.03 \\
Year 2017 & 0.29 & 0.097 & 2.99 & $<0.01$ \\
\hline
\end{tabular}

During SAI-2015, 192 brown trout and 172 Atlantic salmon were caught using the two waveforms and four frequencies. During SAI-2017, 130 brown trout and 298 Atlantic salmon were caught using one waveform and four frequencies. Waveform influenced CPUE significantly (Tab. 4). The occurrence of salmonids decreased when using PEC, when roots were absent and as depth decreased (Tab. 4A, Fig. 5A). With PEC, 50\% fewer fish occurrences were detected than with the other waveforms. Moreover, non-null CPUE decreased in 2015 when using PEC, when roots were absent, and as depth decreased (Tab. 4B, Fig. 5B). With PEC, CPUE was $50 \%$ lower than those with the other waveforms. The effect of year was nested with that of power density. There was a year and/or density effect on the non-null CPUE but not on 


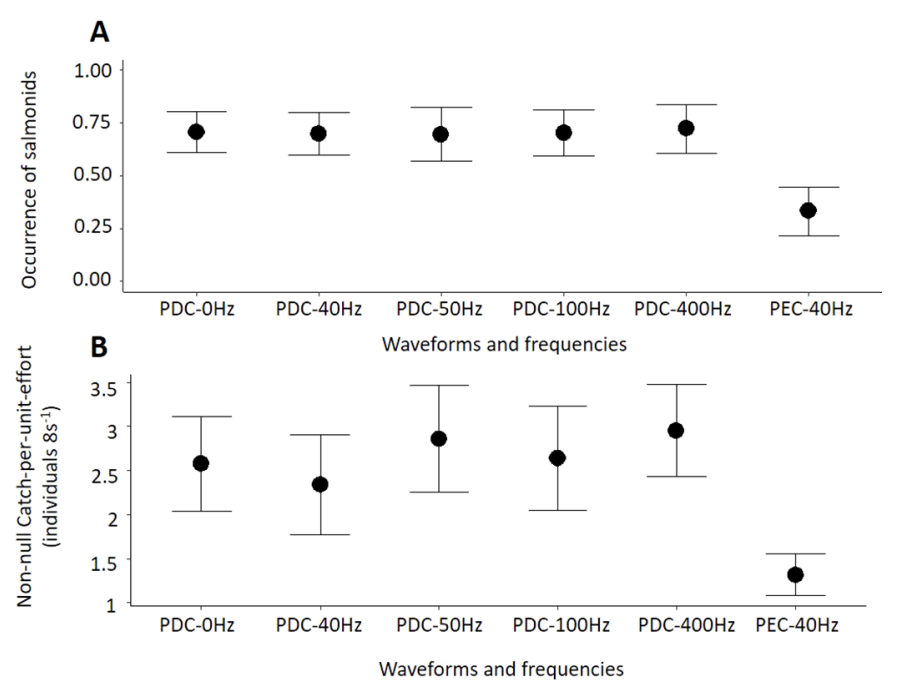

Fig. 5. Estimates of the (A) occurrence and (B) non-null catch-perunit-effort of salmonids by waveform and frequency. Results are means \pm 1 SD. N: 384 . With Cohen's effect: 0.2; statistical power: 1 .

Table 5. Modelling the occurrence of spinal damage in salmonids as a function of biological and environmental variables and frequency. $\mathrm{N}$ : 585. With Cohen's effect: 0.2 ; statistical power: 1 .

\begin{tabular}{lclrl}
\hline & Estimate & Standard Error & $\mathrm{Z}$ value & $\mathrm{P}$ value \\
\hline Intercept & -4.13 & 0.41 & -10.15 & $<0.001$ \\
Roots & 0.84 & 0.30 & 2.80 & $<0.01$ \\
Frequency & 0.0030 & 0.00091 & 3.31 & $<0.001$ \\
Fork length & 0.011 & 0.0028 & 3.98 & $<0.001$ \\
\hline
\end{tabular}

the occurrence of salmonids (Tab. 4B). Indeed, more fishes were caught in 2017 , when the power density was higher than in 2015.

\subsection{Physical damages}

No direct mortality was observed in any of the protocols. Concerning the EAI, 1 eel of $23(4.3 \%), 1$ eel of $9(11.1 \%)$, 2 eels of $22(9.1 \%)$ and 0 of $1(0 \%)$ eels showed evidence of spinal damage when caught with DC, PDC-20Hz, PDC- $400 \mathrm{~Hz}$ and PEC-20Hz, respectively.

For both SAI-2015 and SAI-2017, 57 of 585 (9.7\%) salmonids showed evidence of spinal damage. The percentage of spinal injuries increased significantly when roots were present and as frequency and fork length increased (Tab. 5; Fig. 6).

\section{Discussion}

This study compared in the field the attraction and impact of different waveforms and frequencies on fishes when electrofishing. To compare effects of different waveforms on the attraction or impact of an electric field on fishes, Lamarque (1990) recommended using DC as a standard. Because producing DC with a battery in the field is challenging

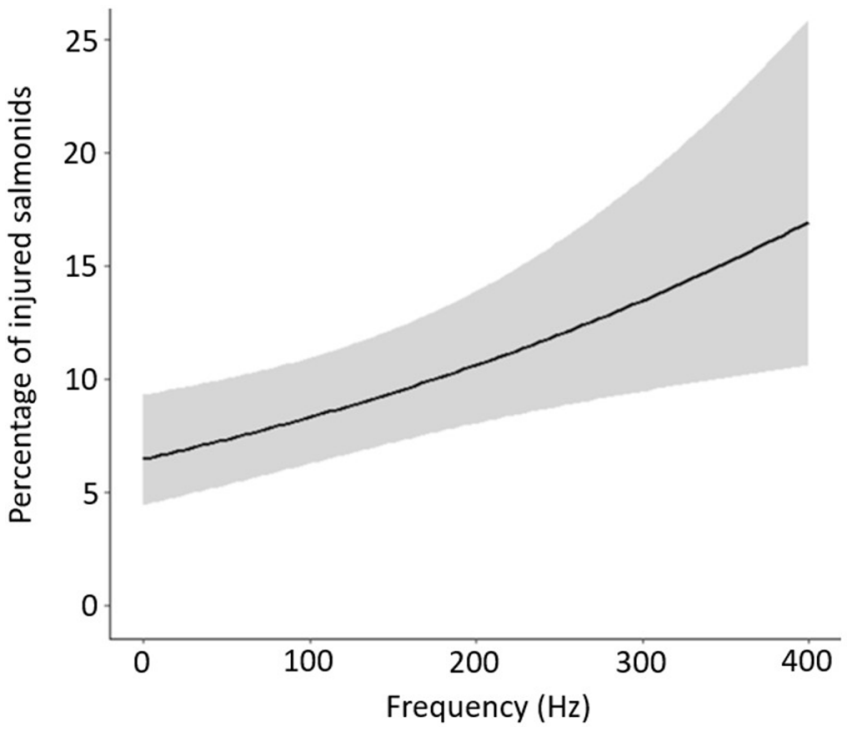

Fig. 6. Estimated percentage of spinal damage in salmonids by frequency. Fork length was fixed at $89 \mathrm{~mm}$ (the mean) and the occurrence of roots was fixed at 0.44 (the mean). Grey bands: $\pm 95 \%$ confidence interval of the frequency effect. A frequency of $0 \mathrm{~Hz}$ corresponded to DC. N: 585 . With Cohen's effect: 0.2; statistical power: 1 .

because it requires a large amount of power, several studies did not consider DC. In the present study, the backpack electrofishers that produce pulsed currents were powered by a battery, while the one that produced DC was powered by a petrolpowered generator. We were thus able to compare a wide range of frequencies $(0-400 \mathrm{~Hz})$ using $\mathrm{DC}$ as a standard.

In the present study, although the output voltage at the anode remained constant while fishing, the RADAC may have varied slightly (Tab. 2). The type of substrate can influence propagation of the electric field from the anode (Scholten, 2003; Pottier, 2017). Side effects (e.g. surface tension, variability in the topography of the riverbed and bank) can also alter the pattern of equipotential lines (Novotny and Priegel, 1974; Beaumont et al., 2005). The power transferred into fishes (Kolz, 1989) was not estimated because the debate between using DC or a pulsed current still contains contradictions (Henry and Grizzle, 2006). Likewise, the conductivity of most freshwater fish species is not known well enough to resolve this debate completely. Furthermore, in situ, dispersion of the electric field in the water depends on the duty cycle (Pottier et al., 2020), which makes the power-transfer theory complicated to calculate when using PDC. However, in the ambient conductivity range of $145-207 \mu \mathrm{S} \mathrm{cm}^{-1}$, the present study had the advantage of providing an equal RADAC regardless of the frequency of $\mathrm{PDC}$ (considering that $0 \mathrm{~Hz}$ is DC) or the anode and cathode on the electrofisher (Pottier et al., 2020). Because equal RADACs yielded the same sampling effort, they allowed for replicability and comparison of different waveforms and frequencies among sampling points.

The type of waveform significantly influenced fish occurrence and non-null CPUE at the sampling points for the European eel and salmonids (Atlantic salmon and brown trout). When performing the EAI and the SAI protocols, 
DC and the different frequencies of PDC obtained the same occurrences of fishes and non-null CPUEs, which were higher than those obtained by PEC. These results agree with those obtained under experimental conditions by Beaumont et al. (2000), who found that PEC captured rainbow trout less efficiently than other forms of pulsed currents. Using DC as a reference, the present study confirmed this trend in the field and for species with different morphologies. Lamarque et al. (1975) theorized that there is a "useful time" for applying current to induce a reaction in fishes. Using a low duty cycle (i.e. the percentage of a period during which the signal exceeds $0 \mathrm{~V}$ ) means that the power emitted into the water and then transferred into fishes may be too low to trigger an anodic curve, which forces fishes to swim towards the anode. The mathematical integral of the PEC pattern may be insufficient to excite spinal nerves, which may explain why the PEC, with a rapid discharge, did not attract fishes. For instance, for SAI2015 , the discharge time of the PEC- $40 \mathrm{~Hz}$ was $2 \mathrm{~ms}$, which would correspond to a duty cycle of $8 \%$ for a PDC pattern. In comparison, that of PDC- $100 \mathrm{~Hz}$ was estimated at $6.2 \%$ and that of PDC- $40 \mathrm{~Hz}$ at $25 \%$. Voltage decreases during a PEC discharge, however, so the voltage gradient in the water is probably not sufficient (less than $0.1 \mathrm{~V} \mathrm{~cm}^{-1}$ ) to induce a neuromuscular reaction in fishes. During depletion captures, Chiaramonte et al. (2020) found greater capture efficiency when they electrofished salmonids with a PDC- $60 \mathrm{~Hz}$ than a PDC-30Hz. This suggests that frequency can influence results (estimation of abundance and capture efficiency with the continual application of electricity) when using depletion sampling, but not, according the present study, when using sampling points (CPUE with a discrete application of electricity).

For both the EAI and SAIs, environmental variables influenced the CPUE. For the EAI, the occurrence and non-null CPUE decreased as depth increased. Depth is usually mentioned as a limiting factor when electrofishing (Bohlin et al., 1989; Beaumont, 2011). When depth increases, fishes can escape from the sight of operators or the attraction field more easily, which decreases capture efficiency. For the EAI, the presence of riparian vegetation decreased CPUE, which is consistent with results of Laffaille et al. (2003), who found that small eels $(<450 \mathrm{~mm}$ long) generally avoided riparian cover. For the SAIs, greater depth and the presence of roots increased CPUE. Both can shelter salmonids (Armstrong et al., 2003), which explain the greater number of fishes observed in this microhabitat.

In this study, fishes were released into their natural environment instead of being necropsied. If a haemorrhage occurred, the visual contrast between blood and coelomic liquid could not have been perceived by ultrasound, especially because many fishes have small coeloms (due to their small size). As a result, although ultrasound could properly identify only spinal injuries, it was determined to be an effective tool for doing so. It should not be forgotten, however, that capture and manipulation can also cause spinal damage. Beaumont et al. (2000) demonstrated that brown trout exposed to PEC or PDC showed no difference in their plasma concentration of cortisol (a stress hormone). In contrast to their study, ultrasound in the present study revealed an effect of the type of waveform on spinal injuries in fishes. The present study suggests that ultrasound is a less invasive method to detect injuries in fishes than necropsy or assessing plasma cortisol concentrations.

Sharber and Carothers (1988) found $44 \%, 44 \%$ and $67 \%$ of rainbow trout with spinal injuries (detected with X-rays) when caught with PEC, PDC or quarter sinusoidal current, respectively (all of which peaked at $260 \mathrm{~V}$ ). In comparison, the percentage of injured individuals in the present study was approximately half that observed by Sharber and Carothers (1988). The risk of injury increases if fishes remain in the electric field too long (Snyder, 2003). The unknown time of exposure and longer total fish length (mean of $320 \mathrm{~mm}$ ) in the study of Sharber and Carothers (1988) may explain that study's larger percentage of spinal injuries. In the present study, all sampling points had the same duration for each protocol (30 and 8 seconds for EAI and SAIs respectively).

Several studies agree that increasing the frequency increases the percentage of injured fishes (McMichael, 1993; Sharber et al., 1994; Dalbey et al., 1996; Dolan et al., 2002). The present study demonstrated that the percentage of spinal injuries to salmonids was not influenced by the waveform, but did increase as frequency increased. A similar trend was observed for the eels, although it was not statistically significant. This study highlights the influence of frequency while considering biological and environmental variables. Larger salmonids had a higher probability of being injured, which agrees with results of Dalbey et al. (1996), who found that the incidence and severity of injury were positively correlated with the length of rainbow trout. Indeed, when a fish is pointed towards the anode, the longer its fork length, the more it is subject to a strong voltage gradient. Furthermore, the power densities used in this study did not influence the percentage of injured fishes, which suggests that the voltage gradient through fishes is the main variable that influences injury. Thus, when electrofishing, it is imperative to quickly catch large fishes with nets. Our results revealed that the presence of roots also increased the percentage of injured salmonids. Indeed, fishes were larger in microhabitats with roots and thus, likely to have a higher probability of suffering spinal damage. Consequently, special care must be taken when catching fishes around roots. Because different environments (e.g. macrophytes, helophytes, woody debris and boulders) can shelter some fishes, we hypothesized that they might influence CPUE and the percentage of injured fishes, but they did not. They were less present than roots or riparian vegetation, which may explain why their potential effects were not significant.

Although attraction remained the same for eels and salmonids regardless of the frequency, increasing the frequency increased the percentage of injured fishes. By assessing the attraction and fish injury of survey protocols, this study provides compelling evidence that setting an electrofishing device requires a trade-off should between DC and PDC. This trade-off concerns the weight of a backpack electrofisher: those that produce DC are usually heavier (ca.15 kg) but less harmful than those that produce PDC (ca. $10 \mathrm{~kg}$ ).

Halsband (1968) suggested $20 \mathrm{~Hz}$ and $80 \mathrm{~Hz}$ as optimal frequencies at which to fish for eel and trout, respectively, when using pulsed current (i.e. using the smallest amount of energy to tetanize fish). The present study showed that frequency did not influence CPUE. We thus recommend using $\mathrm{DC}(0 \mathrm{~Hz})$ to obtain good capture efficiency while minimizing 
the impact on fish. When using DC is not possible, PDC should be used, but at a low frequency. As increasing the frequency was more harmful to fishes (significantly so for salmonids), frequencies should not reach or exceed $100 \mathrm{~Hz}$. Regardless of intercalibration among electrofishers, PEC is not recommended because of its low attraction for fish. For longitudinal surveys, the results show that electrofishers that produce DC or PDC (with of $0-400 \mathrm{~Hz}$ ) can be used interchangeably because their influence on the CPUE of eels and salmonids should not differ.

Finally, this study involved separate sampling efforts for eels and salmonids, each optimized for the target species, after which injuries were assessed. This sampling method impacts not only the target species, but also fish communities. Because species react differently when electrified (e.g. immobilizing smaller species requires higher power densities to be immobilized; Lutnesky et al., 2019), additional taxa need to be evaluated to assess the overall impact of electrofishing on fish communities.

By comparing the efficiency and impact of different waveforms using sampling points in the field, this study provides recommendations for fine tuning electrofishing protocols while considering biological and environmental variables. With the emergence of new waveforms such as the burst PDC (with two adjustable frequencies) and the long-term use of electrofishing, it is important to continue to examine the use of electricity by combining aspects of attraction and of impacts on fishes.

Acknowledgments. This study benefited from support from the PEARL platform of INRAE (1036, U3E), the ANR via the "Investments for the future" program, the National Infrastructure in Health Biology "ANAEE-Services" (ANR-11-INBS0001) and financial support from the OFB INRAE Gest'Aqua pole. The experiments also resulted from collaboration in the field between the INRAE (U3E, ESE), OFB, Departmental Fisheries (departments 22, 29, 35, 44 and 56), environmental associations (BGM, LOGRAMI) and Agrocampus Ouest Rennes.

\section{References}

Armstrong JD, Kemp PS, Kennedy GJA, Ladle M, Milner NJ. 2003. Habitat requirements of Atlantic salmon and brown trout in rivers and streams. Fish Res 62: 143-170.

Beaumont WRC. 2011. Electric fishing: a complete guide to theory and practice, Game \& Wildlife Conservation Trust, Wareham, 98 p.

Beaumont WRC, Lee MJ, Rouen MA. 2000. An evaluation of some electrical waveforms and voltages used for electric fishing; with special reference to their use in backpack electric fishing gear. J Fish Biol 57: 433-444.

Beaumont WRC, Lee MJ, Peirson G. 2005. The equivalent resistance and power requirements of electric fishing electrodes. Fish Manag Ecol 12: 37-43.

Bohlin T, Hamrin S, Heggberget TG, Rasmussen G, Saltveit SJ. 1989. Electrofishing - Theory and practice with special emphasis on salmonids. Hydrobiologia 173: 9-43.

Bozzetti M, Schulz UH. 2004. An index of biotic integrity based on fish assemblages for subtropical streams in southern Brazil. Hydrobiologia 529: 133-144.
Chiaramonte LV, Meyer KA, Branigan PR, Reynolds JB. 2020. Effect of pulsed DC frequency on capture efficiency and spinal injury of trout in small streams. North Am J Fish Manag 40: 691-699.

Cuinat R. 1968. Contribution à l'étude de quelques paramètres physiques dans la pêche électrique en courant continu, en rivière. Applications de l'électricité à la biologie et à l'aménagement des pêches continentales. Symposium de Belgrade, mai 1966, Organisation des Nations Unies pour l'Alimentation et l'Agriculture. INRA, Paris, 145-180.

Dalbey SR, McMahon TE, Fredenberg W. 1996. Effect of electrofishing pulse shape and electrofishing-induced spinal injury on long-term growth and survival of wild rainbow trout. North Am $J$ Fish Manag 16: 560-569.

Dolan CR, Miranda LE, Henry TB. 2002. Electrofishing for Crappies: Electrical Settings Influence Immobilization Efficiency, Injury, and Mortality. North Am J Fish Manag 22: 1442-1451.

Gatz AJJ, Loar JM, Cada CF. 1986. Effects of repeated electroshocking on instantaneous growth of trout. North Am J Fish Manag 6: $176-182$

Gelman A, Yu-Sung S. 2018. Data Analysis Using Regression and Multilevel/Hierarchical Models. https://cran.r-project.org/web/ packages/arm/arm.pdf (accessed July 25, 2018).

Germis G. 2016. Méthode de pêche électrique par échantillonnage par point au Martin-Pêcheur "Indice d'Abondance Anguille". Protocole 2009 actualisé avril 2016. Bretagne Grands Migrateurs.

Gosset C, Lamarque P, Charlon N, Garaïcoechea C. 1971. Un nouvel appareil de péche électrique portable: le "Martin-Pêcheur." Bull Fr Piscic 242: 34-46.

Growns IO, Pollard DA, Harris JH. 1996. A comparison of electric fishing and gillnetting to examine the effects of anthropogenic disturbance on riverine fish communities. Fish Manag Ecol 3: $13-24$.

Halsband E. 1968. Principes fondamentaux de la pêche à l'électricité. Applications de l'électricité à la biologie et à l'aménagement des pêches continentales. Symposium de Belgrade, mai 1966, Organisation des Nations Unies pour l'Alimentation et l'Agriculture. INRA, Paris, 79-85.

Henry TB, Grizzle JM. 2006. Electric-induced mortality of newly transformed juvenile fishes in waters of different conductivity. J Fish Biol 68: 747-758.

Hollender BA, Carline RF. 1994. Injury to wild brook trout by backpack electrofishing. North Am J Fish Manag 14: 643-649.

Jha BR, Gurung S, Khatri K, Gurung A, Thapa AKCM, Gurung B, Acharya S. 2018. Patterns of diversity and conservation status of freshwater fishes in the glacial fed and rain fed rivers of Eastern Nepal. Environ Biol Fishes 101: 1295-1305.

Kolz AL. 1989. A power transfer theory for electrofishing. Electrofishing, a power related phenomenon. Fish and Wildlife Technical ReportUnited States Department of the Interior Fish and Wildlife Service, Washington, D.C., U.S.A.

Kolz AL, Reynolds JB. 1989. Determination of power threshold response curves. Fish Wildl Serv Tech Rep US Dep Inter Fish Wildl Serv Wash DC USA 22: 15-24.

Laffaille P, Feunteun E, Baisez A, Robinet T, Acou A, Legault A, Lek S. 2003. Spatial organisation of European eel (Anguilla anguilla L.) in a small catchment. Ecol Freshw Fish 12: 254-264.

Lamarque P. 1968. Electrophysiologie du poisson soumis à l'action d'un champ électrique. Applications de l'électricité à la biologie et à l'aménagement des pêches continentales. Symposium de Belgrade, mai 1966. Organisation des Nations Unies pour l'Alimentation et l'Agriculture. INRA, Paris. 87-110. 
Lamarque P. 1990. Electrophysiology of fish in electric field. Fishing with electricity, applications in freshwater fisheries management, Oxford, England. 4-33.

Lamarque P, Therezien Y, Charlon N. 1975. Etude des conditions de la pêche à l'électricité dans les eaux tropicales. Bull Cent Détudes Rech Sci Biarritz 10: 405-665.

Lutnesky MMF, Cradock KR, Reynolds JB. 2019. Immobilization Threshold and Fish Conductivity of Two Small Fishes. North Am J Fish Manag 39: 788-792.

Maunder MN, Punt AE. 2004. Standardizing catch and effort data: a review of recent approaches. Fish Res 70: 141-159.

McMichael GA. 1993. Examination of Electrofishing Injury and Short-Term Mortality in Hatchery Rainbow Trout. North Am J Fish Manag 13: 229-233.

Mesa MG, Schreck CB. 1989. Electrofishing mark-recapture and depletion methodologies evoke behavioral and physiological changes in cutthroat trout. Trans Am Fish Soc 118: 644-658.

Novotny DW, Priegel GR. 1974. Electrofishing boats: Improved designs and operational guidelines to increase the effectivenessof boom shockers. Technical Bulletin No. 73wisconsin Department of Natural Resources.

Penczak T, Gomes LC, Bini LM, Agostinho AA. 1998. The importance of qualitative inventory sampling using electric fishing and nets in a large, tropical river (Brazil). Hydrobiologia 389: $89-100$.

Pottier G. 2017. Influence du substrat sur la propagation dans l'eau d'un champ électrique produit par un engin de pêche électrique. Cah Tech INRA 91: 7 pages.

Pottier G, Marchand F, Beaulaton L. 2020. A comprehensive guide to set up correctly an electrofishing gear. Environ Monit Assess 192: 22.
Prévost E, Baglinière J-L. 1995. Présentation et premiers éléments de mise au point d'une méthode simple d'évaluation du recrutement en juvéniles de saumon atlantique (Salmo salar) de l'année en eau courante. Les recherches françaises en évaluation quantitative et modélisation des ressources et des systèmes halieutiques: actes du colloque, ORSTOM, Paris. 39-48.

R Development Core Team. 2011. R: A Language and Environment for Statistical Computing. Vienna: R Foundation for Statistical Computing. http://www.r-project.org/ (accessed August 25, 2015).

Scholten M. 2003. Efficiency of point abundance sampling by electrofishing modified for short fishes. J Appl Ichthyol 19: 265-277.

Sharber NG, Carothers SW. 1988. Influence of electrofishing pulse shape on spinal injuries in adult rainbow trout. North Am J Fish Manag 8: 117-122.

Sharber NG, Carothers SW, Sharber JP, De Vos JC, House DA. 1994. Reducing Electrofishing-induced injury of Rainbow trout. North Am J Fish Manag 14: 340-346.

Snyder DE. 2003. Electrofishing and its harmful effects on fish. Information and Technology Report USGS/BRD/ITR2003-0002U.S. Geological Survey Biological Resources Division. U.S. Government Printing Office, Denver, CO.

Tomanova S, Tedesco PA, Roset N, Berrebi dit Thomas R, Belliard J. 2013. Systematic point sampling of fish communities in mediumand large-sized rivers: sampling procedure and effort. Fish Manag Ecol 20: 533-543.

Vehanen T, Sutela T, Jounela P, Huusko A, Mäki-Petäys A. 2013. Assessing electric fishing sampling effort to estimate stream fish assemblage attributes. Fish Manag Ecol 20: 10-20.

Wellemeyer JC, Perkin JS, Fore JD, Boyd C. 2018. Comparing assembly processes for multimetric indices of biotic integrity. Ecol Indic 89: 590-609.

Cite this article as: Pottier G, Nevoux M, Marchand F. 2020. Electrofishing eel, salmon and trout: impact of waveform and frequency on capture-per-unit-effort and spinal damage. Knowl. Manag. Aquat. Ecosyst., 421, 42. 